\title{
Mário de Andrade e a especificidade do gênero epistolar: 0 esboço de uma teoria
}

\author{
[ Mário de Andrade and epistolary genre specificity: the outline of a theory
}

\author{
Maria Regina Barcelos Bettiol ${ }^{\mathrm{x}}$
}

\begin{abstract}
RESUMO - A correspondência do escritor Mário de Andrade foi a mais representativa do século XX. Mário em seu exercício epistolar ou, melhor dizendo, em sua intermediação entre teoria e práxis, mesmo de forma pouco sistematizada, esboça os contornos de uma teoria sobre o gênero epistolar, discute a especificidade do gênero, o seu trânsito pela esfera do literário e aconselha ainda os jovens escritores brasileiros a começar o seu ingresso no mundo das letras pelo texto epistolar. A concepção de gênero epistolar de Andrade se inscreve numa noção mais ampla que entende o epistolar como um gênero híbrido propício à eclosão de outras formas literárias devendo, portanto, ser praticado por todos os nossos escritores e pensado igualmente como um gênero de vital importância para compreendermos o processo de formação da Literatura Brasileira. · PALAVRAS-CHAVE • Gênero epistolar; história; especificidade; hibridismo;
\end{abstract}

\begin{abstract}
Literatura Brasileira. • ABSTRACT - The correspondence of writer Mario de Andrade was the most representative of the twentieth century, in his epistolary exercise. Rather, in his mediation between theory and practice, even in his not very systematic manner, the author outlines a theory on the epistolary genre, discusses the specificity of the genre, its transit through the literary sphere and also advises the young Brazilian writers to step into the world of letters by the epistolary text. The Andrade's design of the epistolary genre is part of a broader notion that understands the epistolary as a hybrid genre conducive to the outbreak of other literary forms. It must therefore be practiced by all our writers and also thought as a genre of vital importance to understand the process of formation of Brazilian literature. KEYWORDS. Epistolary genre; history; specificity; hybridity; Brazilian literature.
\end{abstract}

Recebido em 24 de fevereiro de 2016

Aprovado em 6 de dezembro de 2016

BETTIOL, Maria Regina Barcelos. Mário de Andrade e a especificidade do gênero epistolar: o esboço de uma teoria. Revista do Instituto de Estudos Brasileiros, Brasil, n. 65, p. 227-236, dez. 2016.

DOI: http://dx.doi.org/Io.II606/issn.23I6-90IX.voi65p227-236

I Universidade Regional Integrada do Alto Uruguai e das Missões (URI, Rio Grande do Sul, Brasil). 
Mário de Andrade escreveu cartas, centenas de cartas que vêm enchendo volumes. Foi indiscutivelmente o mais importante epistológrafo brasileiro do século XX e um dos mais representativos da história da epistolografia mundial. Ao examinarmos a sua vasta correspondência, encontramos "pistas" sobre a história e a prática do gênero epistolar no Brasil num período em que a correspondência trocada entre os nossos escritores não era objeto de estudo.

Nas últimas décadas, os críticos literários brasileiros têm se preocupado em reunir o corpus epistolar dos nossos escritores, que passa a ser estudado como uma forma de acedermos à criação da obra de um autor². Ainda que não tenha feito um estudo sistematizado, Mário foi um dos primeiros escritores brasileiros a pensar sobre a especificidade do gênero epistolar. Assim, selecionamos trechos de algumas cartas do escritor que podem servir de ponto de partida para pensarmos a história da epistolografia em nosso país.

\section{A definição da Carta segundo Mário de Andrade}

No campo da Literatura Brasileira encontramos grandes epistológrafos, como Alceu Amoroso Lima, Luís da Câmara Cascudo, Carlos Drummond de Andrade, Otto Lara Resende, mas, em termos de produção epistolar, Mário de Andrade é o que mais se destaca. Em suas constantes análises, afirmou ao amigo Carlos Drummond de Andrade em Io de novembro de I924: "Desculpe esta longuidão de carta. Eu sofro de gigantismo epistolar"3. Essa carta foi o prenúncio de uma produção epistolar que atingiu um gigantismo dado o número de destinatários, assuntos tratados e projetos estéticos desenvolvidos.

2 "Reunir o corpus epistolar dos nossos escritores é imprescindível para 'visualizar os meandros da Teoria Literária e aclarar as poéticas de cada escritor.'” SANTIAGO, Silviano (Org.). Carlos e Mário: correspondência entre Carlos Drummond de Andrade e Mário de Andrade. Prefácio e notas de Silviano Santiago. Organização e pesquisa iconográfica de Lélia Coelho Frota. Rio de Janeiro: Bem-te-vi, 2002, p. Io.

3 ANDRADE, Mário de. A lição do amigo: cartas de Mário de Andrade a Carlos Drummond de Andrade. São Paulo: Companhia das Letras, 20I5, p. 22. 
Em outra carta, escrita a Henriqueta Lisboa, datada de 22 de março de I942, confessou sofrer de "epistolomania", a "mania de escrever cartas": "A epistolomania foi interrompida pelo almoço de família [...]. Depois continuei escrevendo cartas e uma creio que saiu boa, não reli"^. Em outras palavras, a necessidade de se comunicar com os seus semelhantes, de trocar impressões, de debater sobre questões de seu tempo, fez com que o espaço epistolar se tornasse propício para reflexões sobre a vida e a arte.

Contudo, cabe aqui definirmos o nosso objeto de estudo: a carta. Na concepção de Mário: “Puxar conversa' não é diferente de trocar cartas. Puxar conversa na rua é o modo de se aproximar agressiva e despudoramente, sensual e fraternamente, do outro, para que o outro, ao passar de objeto a sujeito, transforme o sujeito que puxara a conversa em objeto"s. Marcos Antonio de Moraes afirma:

Poucas vezes Mário de Andrade teorizou sobre o fazer epistolográfico, visto por ele como uma "paixão sublime". Entretanto, a práxis epistolar e algumas de suas ponderações fragmentárias sobre o tema, esparsas em sua correspondência ou na produção literária, poderiam desenhar a sombra de uma teoria, ou pelo menos circunscrever o epistológrafo enfrentando pontos espinhosos dessa escritura tão escorregadia em seus limites discursivos ${ }^{6}$.

A teoria epistolar do escritor se filia à concepção defendida pela escola clássica de epistolografia em que a carta é vista como sermo, diálogo7. A nossa observação é reforçada por Marcos Antonio de Moraes, que assevera que a carta, na visão de Mário, situava-se para além da comunicação prosaico-imediatista ou das cortesias sociais:

Mário, em suas cartas, deseja empregar os recursos da oralidade - o "falar simples" - não importando que o estilo resultante lhe pareça "besta" e a mensagem, cheia de repetições. Quando o carteador percebe uma queda acentuada para o discurso inerente à palavra escrita - uma mudança de tom -, descobre a inabilidade no uso do gênero ${ }^{8}$.

Nesse processo de definição da carta, Mário ainda fez questão de sublinhar a diferença entre carta e bilhete: "A mim também, como a todo sujeito que escreve cartas que não são apenas recados, me perturba sempre e me empobrece o problema infamante do 'estilo epistolar"'. Ora, essa distinção entre carta e bilhete é feita por

4 ANDRADE, Mário de. Querida Henriqueta: cartas de Mário de Andrade a Henriqueta Lisboa. Ed. prep. por padre Lauro Palú. Rio de Janeiro: José Olympio, I990, p. 84.

5 SANTIAGO, Silviano, op. cit., p. 48.

6 MORAES, Marcos Antonio de. Orgulho de jamais aconselhar. A epistolografia de Mário de Andrade. São Paulo: Edusp, 2007, p. 70.

7 A esse respeito ler: DEMETRIUS. On style (Trad). Londres: Harvard University Press, I973.

8 MORAES, Marcos Antonio de, 2007, op. cit, p. 72.

9 Apud MORAES, Marco Antonio de, 2007,op. cit., p 72. 
conhecidos estudiosos do gênero epistolar, como, por exemplo, Marie-Claire Grassi ${ }^{\mathrm{i}}$. Resumidamente, podemos dizer que, para a referida autora, o bilhete, embora seja uma pequena carta ou, mais precisamente, uma carta em miniatura, não pode ser confundido com a carta justamente por ser escrito sem cerimônia, sem observar normas.

Sabemos que condição sine qua non do gênero epistolar é o diálogo entre o emissor e o destinatário - o texto epistolar é um texto escrito a quatro mãos; torna-se imperativo responder à carta recebida para que o pacto epistolar estabelecido entre emissor e destinatário não seja rompido. Mário, ciente da necessidade de preservar o pacto epistolar com seus destinatários, confidenciou à amiga Henriqueta Lisboa: "Uma carta não respondida me queima, me deixa impossível de viver, me persegue. Algumas não respondo, me exercito, ou condeno por inúteis. Me queimam, me perseguem tanto hoje como as deixadas sem resposta, vinte anos atrás"זr.

Sentia-se angustiado com a impossibilidade de responder a todos os destinatários. Em I6 de fevereiro de I945, Mário relatou ao amigo Guilherme de Figueiredo: "Não é verdade mais que eu responda a todas as cartas [...]. E este remorso difuso eu sei que não se acabará, porque a cada carta não respondida, a cada livro não agradecido, o remorso se reimpõe com a mesma inexorabilidade!"ז2

Logo, a interrupção ou rompimento do pacto epistolar era algo que incomodava o escritor, pois significava a impossibilidade de dialogar, de puxar conversa com os seus destinatários ${ }^{\mathrm{I3}}$, daí podemos concluir que a carta na concepção mariodeandradiana era muito mais do que um simples pedaço de papel, de um ato burocrático, mas um exercício de fraternidade, de solidariedade para com os seus semelhantes.

\section{OS ÍNDICES DE IDENTIFICAÇÃO DO GÊNERO EPISTOLAR}

A carta se forma a partir de dados elementos, como emissor, destinatário, data, lugar, assunto, assinatura, sigilo e publicação ${ }^{\mathrm{I}}$, aspectos que encontramos nas cartas redigidas por Mário de Andrade e que pretendemos discutir aqui. No que diz respeito ao emissor, podemos aprofundar o nosso conhecimento sobre o seu perfil biográfico e a sua trajetória profissional. Em tom confessional fala de si, registra as suas impressões, especialmente as suas expectativas em relação ao trabalho. Contudo, o

Io GRASSI, Marie-Claire. Lire l'épistolaire. Paris: Dunod, I998, p. 3.

II ANDRADE, Mário de, I990, op. cit., p. I64.

I2 ANDRADE, Mário de. A lição do Guru: cartas a Guilherme Figueiredo. I937-I945. Ed. prep. pelo destinatário. Rio de Janeiro: Civilização Brasileira, I989, p. I60.

I3 Ler a esse respeito: CAMARGO, Ceci Ribeiro de. Índice temático da correspondência ativa de Mário de Andrade, I9I9-I945. V. I. Porto Alegre: UFRGS, I998. Essa pesquisa, orientada pelo historiador José Augusto Avancine, organizada em três volumes, nos dá a dimensão do número de correspondentes de Mário de Andrade. Para que o leitor tenha conhecimento, apenas no primeiro volume são apresentados 8I destinatários.

I4 ROCHA, Andrée Crabé. A epistolografia em Portugal. Coimbra: Almedina, I965. 
autor não testemunhou apenas episódios da sua vida pessoal, mas também da vida dos seus destinatários.

Nas palavras de Matildes Santos, "A carta não só diz do remetente, como abre brechas para o conhecimento do destinatário, expondo-o através de observações, comentários”ㄷ. A leitura da correspondência de determinado autor nos permite avaliar o tipo de relação que ele mantinha com determinadas pessoas (públicas e anônimas), daí a importância de conhecermos a identidade dos correspondentes.

No tocante à data, a maioria das cartas de Mário de Andrade, com raras exceções, são datadas. Conforme Rocha, a data é importante por várias razões, pois ela situa a carta no tempo de sua feitura. As cartas não têm autonomia textual, só têm verdadeiro sentido na série temporal que as viu nascer, isto é, as cartas estão ligadas às circunstâncias que as determinam, situações históricas e ideológicas ${ }^{16}$. Entretanto, Rocha explica que a correspondência não é um caminho retilíneo, a carta se perde numa série de bifurcações, de temporalidades distintas. Dito de outra forma, existe um tempo cronológico/exterior e um tempo interior, que aparece registrado no texto epistolar através das impressões e sensações do carteador e que não corresponde necessariamente ao tempo cronológico.

Em relação ao lugar, a maioria das cartas de Mário foram escritas em São Paulo, onde residiu, mas, quando porventura viajava, costumava mencionar o nome da cidade que estava visitando naquele momento. Quanto ao assunto tratado nas cartas, podemos dizer que a lista é imensa - conversava sobre os mais variados assuntos, desde os seus projetos literários e artísticos até assuntos corriqueiros, como, por exemplo, algum problema de saúde ou familiar.

No que diz respeito à questão da assinatura, o escritor confidenciou ao amigo Guilherme de Figueiredo, em Iํ de julho de I944, que, em razão de não conseguir mais ler e responder a todas as cartas que recebia, pediu ao seu secretário que falsificasse a sua assinatura: "Sempre o meu secretário é que passa os olhos no livro primeiro [...] a maioria ele mesmo acusa recebimentos, faz uma das várias festinhas que ensinei por norma e falsifica a minha assinatura. Bem isto deve ser escandaloso, não conte pra ninguém”. ${ }^{\text {I7 }}$

Devemos explicar aos leitores e estudiosos do gênero epistolar que, no século XVII, o epistológrafo costumava ter um secretário que imitava a sua caligrafia ${ }^{\text {I8 }}$. Escrevendo por mão alheia, Mário deu continuidade a essa tradição epistolar. E essa informação é de vital relevância para aqueles que se dedicam a organizar a sua correspondência, pois significa que provavelmente encontraremos outros textos que não foram escritos de próprio punho pelo escritor. Apesar disso, por se tratar de mensagem subscrita, a assinatura responsabiliza jurídica, moral e literariamente

I5 SANTOS, Matildes Demétrio dos. Ao sol carta é farol. A correspondência de Mário de Andrade e outros missivistas. São Paulo: Annablume, I998, p. 69-70.

I6 ROCHA, Andrée Crabé, op. cit., p. I6.

I7 ANDRADE, Mário de, I989, op. cit., p. I6o.

I8 FREIRE, Francisco Joseph (Cândido Lusitano). O secretario portuguez. Lisboa: Oficina de Domingos Gonçalves,

I745. 
quem faz uso dela ${ }^{\text {I9 }}$. Portanto, a assinatura é a marca da autoria, assegura a origem, a filiação de um texto.

E finalmente, no que concerne ao sigilo e publicação das cartas, devemos pensar que inicialmente uma carta não era escrita para ser publicada - o sigilo, a confiança e a discrição sempre foram regras respeitadas pelo emissor e pelo destinatário. Nesse sentido, Mário deixou recomendações expressas em relação à sua correspondência, que nem sempre foram observadas. Em poucas palavras, ele fez questão de estabelecer uma diferença precisa entre carta pública e privada, sendo bastante reticente em relação à publicação de suas cartas privadas. $\mathrm{O}$ escritor advertiu ao amigo Manuel Bandeira sobre esse seu desejo: "Por mais que eu escreva agora direto e simples, ainda faço distinção entre escrever pra público e pra amigos. As cartas que mando pra você são suas. Se eu morrer amanhã não quero que você as publique”2o.

Já no final de sua existência, o escritor paulista tinha consciência do volume da sua produção epistolar - vislumbrando a possibilidade de sua correspondência se tornar uma obra para a posteridade - e do perigo que representava para sua vida, e de todos os envolvidos, suas cartas particulares virem a público. Segundo Moraes:

A possibilidade de que esse complexo material, revelador de intimidades e contraditório pela própria natureza, viesse um dia a se tornar público causava-lhe mal-estar. [...]. Parecia-lhe estar realizando uma "infâmia”, devassando ao olhar público o particular, nascido para ser sepultado na carta. Mário ressente-se, nesse momento, que o escritor, o artista, por ter "uma vida pública, não pudesse ter uma vida particular" e dá o veredicto a Murilo Miranda, não enviará as cartas, não permitirá que as publique enquanto viver: “devia ser proibido a mostra pública de cartas particulares, por lei governamental”.

Em 20I5, veio a público uma carta de autoria de Mário de Andrade falando sobre a sua homossexualidade ${ }^{22}$ e gerando algumas polêmicas entre os estudiosos da sua correspondência. Como mencionamos anteriormente, o autor estabeleceu uma nítida diferença entre carta pública e privada, entre cartas publicáveis e não publicáveis. Mário não se refere apenas aos brasileirismos empregados em textos divulgados na imprensa, tinha também certa reserva em relação à sua vida pessoal. Portanto, ignorar essa classificação estabelecida pelo próprio escritor significa desconhecer aspectos da sua teoria epistolar. Evidentemente que existe o direito à informação e que não podemos de forma alguma censurar a publicação de uma carta. Contudo acreditamos que o estudo dessa carta privada poderá ser de maior utilidade para aqueles que se dedicam a estudar a sua biografia, não trazendo, todavia, grandes novidades em relação ao seu processo de criação.

I9 ROCHA, Andrée Crabé, op. cit.

20 Apud MORAES, Marcos Antonio de (Org.). Correspondência Mário de Andrade e Manuel Bandeira. São Paulo: Instituto de Estudos Brasileiros - IEB/USP, 2000, p. I82. (Coleção Correspondência de Mário de Andrade; I).

2I MORAES, Marcos Antonio de, 2007, op. cit., p. II9-I2O.

22 COZER, Raquel. Carta de Mário vetada por herdeiro tem acesso liberado. Folha de S. Paulo. Disponível em: <http://wwwI.folha.uol.com.br>. Acesso em: out. 2016. 


\section{AO ESCREVER CARTAS NÃO ESTAREI FAZENDO LITERATURA?}

Ao vivenciar a práxis epistolar no seu dia a dia, em determinado momento Mário de Andrade começou a questionar se não estaria fazendo literatura:

Aquela pergunta desgraçada "não estarei fazendo literatura"?, "não estarei posando"?, me martiriza também a cada imagem que brota, a cada frase que ficou mais bemfeitinha, e o que é pior, a cada sentimento ou ideia mais nobre e mais intenso. É detestável, e muita coisa que prejudicará a naturalidade das minhas cartas, sobretudo sentimentos sequestrados, discrições estúpidas e processos, exageros, tudo vem de uma naturalidade falsa, criada sem pensar ao léu da escrita pra amainar o ímpeto da sinceridade, da paixão, do amor ${ }^{23}$.

Essa questão levantada pelo autor é a questão central da epistolografia contemporânea, ela é bastante pertinente se pensarmos que as cartas sempre tiveram o seu "passaporte recusado na esfera do literário"². A análise de Mário de Andrade demonstra que o eu, embora carregue a marca da pessoalidade, deve ser entendido como um outro, ou seja, devemos considerar a existência dos autores múltiplos de um mesmo "eu".

Para Matildes Santos, o eu que escreve testemunha e interpreta um outro, que viveu tempos atrás: "Sem dúvida, trata-se da mesma pessoa, mas sempre um outro, modificado pelas vicissitudes do tempo. Como, então, não duvidar que o relato não tinha sido contaminado pela química do imaginário?”25.

$\mathrm{Na}$ mesma linha de reflexão de Matildes Santos, Marcos Antonio de Moraes afiança que há muitas formas de contar-se - esse eu reproduz as imagens da civilização que o concebeu, fazendo, de cada um, "outros":

A experiência comum de quem escreve cartas não ignora que o carteador se modifica em graus diferentes, moldando-se pela imagem que tenciona mostrar ao outro, reflexo não muito distante das ações sociais que modelam o indivíduo em mil facetas da personalidade. Esse caráter particular e intransferível da carta determina um espaço narrativo subterrâneo, protegido pelo segredo, próximo de uma "encenação" do eu, consciente ou apenas movido pela intuição"²6.

Diante do questionamento se estaria fazendo literatura, o autor percebeu que a carta como texto não está isenta de ficcionalidade e que o gênero epistolar, assim como outros gêneros, é híbrido: “Todos os gêneros se baralham, isso até Croce já

23 Apud MORAES, Marcos Antonio de, 2007, op. cit., p. 70.

24 Conforme Diaz, as cartas sempre foram reduzidas ao status subalterno de dados biográficos ou psicológicos, amarradas a um indivíduo, a uma história, reduzidas ao pessoal, ao íntimo, tendo seu passaporte sempre recusado na esfera do literário. DIAZ, Brigite. L'épistolaire ou la pensée nômade. Formes et fonctions de la correspondance dans quelques parcours d'écrivains au XIX. Paris: PUF, 2002, p. 5.

25 SANTOS, Matildes, op. cit., p. 55.

26 MORAES, Marcos Antonio de, 2007, op. cit., p. 75. 
decretou e está certo. Romances que são estudos científicos, poemas que são lirismo, contos que são poemas, histórias que são filosofias" 27.

Devemos acrescentar ainda que Mário é um dos poucos escritores brasileiros a conceder destaque ao gênero epistolar no processo de formação da Literatura Brasileira. Em outras palavras, o experiente epistológrafo Mário de Andrade já apontava a importância do Modernismo na consolidação do gênero epistolar no Brasil e propõe o estudo da Literatura Brasileira através das cartas:

Eu sempre afirmo que a literatura brasileira só principiou escrevendo realmente cartas, com o movimento modernista. Antes, com alguma rara exceção, os escritores brasileiros só faziam "estilo epistolar", oh primores de estilo! Mas as cartas com assunto, falando mal dos outros, xingando, contando coisas, dizendo palavrões, discutindo problemas estéticos e sociais, cartas de pijama, onde as vidas se vivem sem mandar respeitos à excelentíssima esposa do próximo nem descrever crepúsculos, sem dançar minuetos sobre eleições acadêmicas e doenças do fígado: só mesmo com o modernismo se tornaram uma forma espiritual de vida em nossa literatura ${ }^{28}$.

Na análise de Mário, o texto epistolar funciona como intertexto, ajuda a pensar o processo de maturação, de criação da obra literária. No dizer de Moraes:

A carta aparece, assim, estrategicamente, em segundo plano: como exercício que os iniciantes nas letras deveriam praticar antes de se aventurarem no delicado "piano" da criação literária. Era o espaço para o "treino”, o "adestramento" da escrita, para o enfrentamento diário de problemas "técnicos" da arte da palavra [...]. Escrever cartas vale como um conselho aos novos ficcionistas, apressados divulgadores de obras imperfeitas ${ }^{29}$.

Não foi por acaso que Mário recomendou aos jovens escritores o exercício epistolar uma vez que essa prática propicia todas as eclosões literárias. Essa recomendação sinaliza o entendimento, por parte do escritor, de que a carta ocupa inegavelmente um lugar na esfera do literário, por isso a define como "violão da literatura”, uma espécie de estágio do aspirante ao mundo das letras antes de praticar o "piano da criação literária”.

Assim, o conceito de epistolografia desenvolvido pelo autor deve ser entendido à luz de uma teoria do hibridismo. Ele apontava a necessidade de uma reformulação teórica do gênero epistolar pois analisou o gênero epistolar a partir de um outro viés, de uma noção de identidade epistolar móvel, não de uma identidade fixa, ancorada em um único tempo e espaço, mas a partir de seu eterno nomadismo criativo e criador de novas formas.

A grande lição do escritor foi mostrar as armadilhas que o estudo de um gênero traz para a crítica. Como qualquer sistema de gênero, o epistolar repete a história e resiste a ela. A crítica do gênero tem por função consolidar o gênero estabelecido, determinando

27 MORAES, Marcos Antonio de, 2000, op. cit., p. I7.

28 ANDRADE, Mário. Amadeu Amaral. In .O empalhador de passarinho. São Paulo Martins/INL-MEC, I972, p.I82-I83.

29 MORAES, Marcos Antonio de, 2007, op. cit., p. IIO-III. 
sua permanência e autonomia, sua convenção e transgressão. Mário fez mais do que adestrar os jovens escritores no ofício da criação literária, ele propôs uma releitura do gênero epistolar e da forma como vinha sendo praticado no Brasil daquele período.

\section{CONSIDERAÇões FINAIS}

Ao longo do nosso percurso, verificamos que, a exemplo do texto literário, o texto epistolar também exige um trabalho de decodificação. Em outras palavras, a obra literária é destinada a um público de desconhecidos, enquanto a carta é dirigida a determinada pessoa, com quem se divide conhecimentos muito particulares. As cartas de Mário de Andrade foram aqui analisadas dentro de outra situação performativa, ou seja, o pacto epistolar entre remetente e destinatários foi rompido, a carta passou a ser objeto de contemplação teórica de um terceiro, o leitor, transformado numa espécie de voyeur.

Ainda que não tenha propriamente sistematizado a sua teoria epistolar, em seus comentários Mário apresenta o gênero como princípio dinâmico de produção, a carta é lida sob o duplo signo da convenção e da transgressão, no seu duplo estatuto de texto literário e não literário, documento, monumento, dentro de um plano micro e macrotextual, que delimita e excede limites. $\mathrm{O}$ autor soube reconhecer a principal característica do gênero epistolar, que é justamente a sua hibridez, e constatou em suas análises que a carta é um texto que apresenta a própria especificidade e resistente a classificações genéricas.

Para concluir, devemos destacar que muitas cartas de Mário de Andrade estão sendo organizadas em edições críticas, portanto, novas descobertas, novas reflexões poderão surgir da leitura de cartas inéditas. Contudo, saímos com a certeza de que para o escritor a carta é texto escrito a quatro mãos, um processo de criação compartilhada.

SOBRE A AUTORA

MARIA REGINA BARCELOS BETTIOL é doutora em Letras (Littérature Générale et Comparée) pela Université Sorbonne Nouvelle Paris III e pós-doutorada em Teoria da Literatura pela Universidade de Coimbra. Atualmente, é pesquisadora Capes PNPD na Universidade Regional Integrada do Alto Uruguai e das Missões.

Email:mrbettiol@yahoo.com.br 


\section{REFERÊNCIAS BIBLIOGRÁFICAS}

AMARAL, Aracy (Org.). Correspondência Mário de Andrade e Tarsila do Amaral. São Paulo: Edusp/Instituto de Estudos Brasileiros (IEB/USP), 200I. (Coleção Correspondência de Mário de Andrade: 2).

ANDRADE, Mário de. Amadeu Amaral. In: O empalhador de passarinho. São Paulo Martins/INL-MEC,I972. . Cartas a um jovem escritor. De Mário de Andrade a Fernando Sabino. Ed. prep. pelo destinatário. Rio de Janeiro: Record, I98I.

. A lição do guru: cartas a Guilherme Figueiredo.I937-I945. Ed. prep. pelo destinatário. Rio de Janeiro: Civilização Brasileira, I989.

. Querida Henriqueta: cartas de Mário de Andrade a Henriqueta Lisboa. Ed. prep. pelo padre Lauro Palú. Rio de Janeiro: José Olympio, I990.

. Vida literária. São Paulo: Hucitec/Edusp, I993.

. A lição do amigo: cartas de Mário de Andrade a Carlos Drummond de Andrade. São Paulo: Companhia das Letras, 2015 .

ARROU-VIGNOD, Jean-Philippe. Le discours des absents. Paris: Gallimard, I993.

. L'écriture intime. Montreal: Arcade, octobre I986.

BETTIOL, Maria Regina Barcelos. A escritura do intervalo: a poética epistolar de Antônio Vieira. São Leopoldo: Unisinos, 2008.

. O colecionador Mário de Andrade e a defesa do patrimônio artístico nacional. Revista literatura er debate (URI), Frederico Westphalen, v. 9, n. I6, 20I5, p. 57-68.

BOSSIS, Mireille. La lettre à la croisée de l'individuel et du social. Paris: Kimé, I994.

CAMARGO, Ceci Ribeiro de. Índice temático da correspondência ativa de Mário de Andrade: I9I9-I945. Porto Alegre: UFRGS, I998.

COZER, Raquel. Carta de Mário vetada por herdeiro tem acesso liberado. Folha de S. Paulo. Disponível em: <http://wwwI.folha.uol.com.br >. Acesso em: out. 2016.

DEMETRIUS. On style (Trad). Londres: Harvard University Press, I973.

DIAZ, Brigitte. L'épistolaire ou la pensée nomade: formes et fonctions de la correspondance dans quelques parcours d'écrivains au XIXe. Paris: PUF, 2002.

DIAZ, José Luis. Quelle génétique pour les correspondances?. Genesis - Revue internationale de critique génétique, n. I3, Paris, I999, p. II-3I.

GRASSI, Marie-Claire. Lire l'épistolaire. Paris: Dunod, I998.

FREIRE, Francisco Joseph (Cândido Lusitano). O secretario portuguez. Lisboa: Officina de Domingos Gonçalves, I745.

KAUFMANN, Vincent. L'équivoque épistolaire. Paris, Minuit, I990.

MORAES, Marcos Antônio de (Org.). Cartas de Mário de Andrade e Murilo Rubião. Belo Horizonte: UFMG/ IEB/Giordano, I995.

(Org.). Correspondência: Mário de Andrade \& Manuel Bandeira. São Paulo: Instituto de Estudos Brasileiros (IEB/USP), 2000. (Coleção correspondência de Mário de Andrade: I)

. Orgulho de jamais aconselhar. A epistolografia de Mário de Andrade. São Paulo: EDUSP, 2007.

ROCHA, Andrée Crabé. A epistolografia em Portugal. Coimbra: Almedina, I965.

SANTIAGO, Silviano (Org.). Carlos e Mário: correspondência completa entre Carlos Drummond de Andrade e Mário de Andrade. Prefácio e notas de Silviano Santiago. Organização e pesquisa iconográfica de Lélia Coelho Frota. Rio de Janeiro: Bem-Te-Vi, 2002.

SANTOS, Matildes Demétrio dos. Ao Sol Carta é Farol. A correspondência de Mário de Andrade e outros missivistas. São Paulo: Annablume, I998. 